

Scholarly Publisher RS Global Sp. z O.O. ISNI: 0000000484952390

Dolna 17, Warsaw, Poland 00-773

Tel: +48226022703

Email: editorial_office@rsglobal.pl

\begin{tabular}{ll} 
JOURNAL & Science Review \\
\hline p-ISSN & $2544-9346$ \\
\hline e-ISSN & $2544-9443$ \\
\hline PUBLISHER & RS Global Sp. z O.O., Poland
\end{tabular}

COMPLAINTS OF THE PATIENTS WITH SYSTEMIC

$\begin{array}{ll}\text { ARTICLE TITLE } & \text { LUPUS ERYTHEMATOSUS AND ACTIVE } \\ \text { CYTOMEGALOVIRUS AND EPSTEIN-BARR VIRUS }\end{array}$

INFECTION; THEIR DIAGNOSTIC VALUE

$\operatorname{AUTHOR}(\mathbf{S})$

O. Abrahamovych, U. Abrahamovych, S. Guta, O. Synenkyi,

V. Chemes

O. Abrahamovych, U. Abrahamovych, S. Guta, O. Synenkyi,

V. Chemes. (2020) Complaints of the Patients with Systemic

ARTICLE INFO Lupus Erythematosus and Active Cytomegalovirus and Epstein-

Barr Virus Infection; their Diagnostic Value. Science

Review. 7(34). doi: 10.31435/rsglobal_sr/31102020/7222

DOI

https://doi.org/10.31435/rsglobal_sr/31102020/7222

RECEIVED

27 August 2020

ACCEPTED

18 October 2020

PUBLISHED

25 October 2020

LICENSE

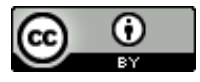

This work is licensed under a Creative Commons Attribution

4.0 International License.

(C) The author(s) 2020. This publication is an open access article. 


\title{
COMPLAINTS OF THE PATIENTS WITH SYSTEMIC LUPUS ERYTHEMATOSUS AND ACTIVE CYTOMEGALOVIRUS AND EPSTEIN-BARR VIRUS INFECTION; THEIR DIAGNOSTIC VALUE
}

\author{
O. Abrahamovych, MD, PhD, Professor, Head of the Department of Internal Medicine \#1 \\ Danylo Halytsky Lviv National Medical University, \\ ORCID ID: http://orcid.org/0000-0001-6862-6809 \\ U. Abrahamovych, MD, PhD, Associate Professor, Department of Internal Medicine \#2 \\ Danylo Halytsky Lviv National Medical University, \\ ORCID ID: https://orcid.org/0000-0003-4762-3857 \\ S. Guta, MD, Assistant Professor, Department of Internal Medicine \#1 \\ Danylo Halytsky Lviv National Medical University, \\ ORCID ID: https://orcid.org/0000-0002-7943-0139 \\ O. Synenkyi, MD, PhD, Head of the Rheumatology Department, Communal Non-profit \\ Enterprise of Lviv Regional Council «Lviv Regional Clinacal Hospital» \\ V. Chemes, MD, Assistant Professor, Department of Internal Medicine \#1 \\ Danylo Halytsky Lviv National Medical University, \\ ORCID ID: https://orcid.org/0000-0002-9584-637X
}

DOI: https://doi.org/10.31435/rsglobal_sr/31102020/7222

\section{ARTICLE INFO}

Received 27 August 2020

Accepted 18 October 2020

Published 25 October 2020

\section{KEYWORDS}

systemic lupus erythematosus, cytomegalovirus,

Epstein Barr virus.

\begin{abstract}
Actuality. The infection with cytomegalovirus (CMV) and Epstein-Barr virus (EBV) in the patients with systemic lupus erythematosus (SLE) is of particular interest to researchers. SLE is a chronic autoimmune disease of unknown etiology that is characterized by multisystemic lesions and is potentially life-threatening $[1,2,3]$.

The severity of the problem is caused by the fact that active viral infection can change the manifestations of SLE, but these changes are not always specific, so primary care physicians have no reason to suspect active virus infection at the first stage of examination of SLE patients and prescribe expensive direct virological tests accordingly.

It has not been definitively established yet which complaints are the most meaningful regarding the presence of active viral infection in patients with SLE.
\end{abstract}

The purpose of the research was to study complaints in SLE patients with active cytomegalovirus and EpsteinBarr virus infection and determine their diagnostic value.

Materials and methods. We randomly enrolled 120 SLE patients - 15 men (12.50\%) and 105 women (87.50\%) aged 18 to 69 years. All patients received treatment at the Rheumatology Department of Lviv Regional Clinical Hospital in 2014-2019. The diagnosis of SLE was established based on the diagnostic criteria of the American College of Rheumatologists (ACR, 1997). In addition, IgM and IgG antibodies to serum viruses were detected for the diagnosis of CMV and EBV infection. To confirm the presence of active viral infection, viruses were detected in media (CMV - urine, blood; EBV - oral mucosa, blood) by polymerase chain reaction, resulting in 28 patients with SLE (23.33\%) detected active CMV infection, in 21 patients with SLE (17.50\%) - active EBV infection and in 15 patients with SLE (12.5\%) - a combination of active CMV and EBV infection.

To achieve the purpose of the study, we identified three steps: the first step was to analyze complaints in patients with SLE with active CMV infection and determine their diagnostic value, the second - in the analysis of complaints in patients with SLE with active EBV infection and clarify their diagnostic values and the third - in the analysis of complaints in patients with SLE with a combination of active CMV and EBV infection and clarification of their diagnostic value. We identified three steps: the first step was to analyze complaints in patients with SLE with active CMV infection and determine their diagnostic value, the second - in the analysis of complaints in patients with SLE with active EBV infection and clarify their diagnostic values and the third in the analysis of complaints in patients with SLE with a combination of active CMV and EBV infection and clarification of their diagnostic value. 
Statistical analysis was performed by calculating the chances of establishing the phase of CMV and EBV infection in patients with SLE, using a separate feature - a marker that can be detected during the initial examination of the patient. The probable probability of active infection was determined using indicators of sensitivity, specificity and accuracy [4]. The actual material was processed on a personal computer in MS Excel and SPSS on the basis of conjugation tables with calculation of diagnostic value indicators. The association between active infection and a particular patient complaint was considered to be confirmed when the coefficient of association exceeded 0.5 (or 0.3 for the coefficient of contingency).

Research results. It was found that in patients with SLE the presence of active cytomegalovirus infection among the main complaints significantly more often indicate the presence of myalgias (coefficient of association 0.79 ) or fever (0.51), or chills of the extremities (0.51), or arthralgia (coefficient of contingent 0.31 ). The presence of active virus Epstein - Barr infections are significantly more often evidenced by the presence of myalgias (coefficient of contingent 0.31 ) or sleep disorders (coefficient of association 0.84 ), or mood swings $(0.74)$, or fever $(0.61)$, or the appearance of new rashes (0.53). On the presence of a combination of active cytomegalovirus and virus Epstein Barr infections significantly more often indicate complaints of sleep disturbances (coefficient of association 0.97) or mood swings (0.83), or a feeling of dryness in the eyes $(0.51)$, or fever $(0.50)$.

Conclusions. The presence of active cytomegalovirus infection in patients with systemic lupus erythematosus among the main complaints often indicates the presence of myalgias or fever, or chills of the extremities, or arthralgia, the presence of active virus Epstein - Barr infection - myalgia or sleep disturbances, or mood swings, or fever, or the appearance of new rashes, the presence of their combination - sleep disturbances or mood swings, or a feeling of dryness in the eyes, or fever, which can be used in the diagnostic algorithm.

The established patterns of complaints allow us to reasonably suspect in patients with systemic lupus erythematosus the presence of active cytomegalovirus and Epstein-Barr virus infection, the final verification of which requires the use of direct serological tests.

Citation: O. Abrahamovych, U. Abrahamovych, S. Guta, O. Synenkyi, V. Chemes. (2020) Complaints of the Patients with Systemic Lupus Erythematosus and Active Cytomegalovirus and Epstein-Barr Virus Infection; their Diagnostic Value. Science Review.7(34). doi: 10.31435/rsglobal_sr/31102020/7222

Copyright: (C) 2020 O. Abrahamovych, U. Abrahamovych, S. Guta, O. Synenkyi, V. Chemes. This is an open-access article distributed under the terms of the Creative Commons Attribution License (CC BY). The use, distribution or reproduction in other forums is permitted, provided the original author(s) or licensor are credited and that the original publication in this journal is cited, in accordance with accepted academic practice. No use, distribution or reproduction is permitted which does not comply with these terms.

Actuality. The infection with cytomegalovirus (CMV) and Epstein-Barr virus (EBV) in the patients with systemic lupus erythematosus (SLE) is of particular interest to researchers. SLE is a chronic autoimmune disease of unknown etiology that is characterized by multisystemic lesions and is potentially life-threatening $[1,2,3]$.

The severity of the problem is caused by the fact that active viral infection can change the manifestations of SLE, but these changes are not always specific, so primary care physicians have no reason to suspect active virus infection at the first stage of examination of SLE patients and prescribe expensive direct virological tests accordingly.

It has not been definitively established yet which complaints are the most meaningful regarding the presence of active viral infection in patients with SLE.

The purpose of the research was to study complaints in SLE patients with active cytomegalovirus and Epstein-Barr virus infection and determine their diagnostic value.

Materials and methods. We randomly enrolled 120 SLE patients - 15 men (12.50\%) and 105 women $(87.50 \%$ ) aged 18 to 69 years (the average age $39.38 \pm 12.40$ ). All patients received treatment at the Rheumatology Department of Lviv Regional Clinical Hospital in 2013-2016. The patients underwent comprehensive clinical, laboratory and instrumental examinations of their organs and systems and were diagnosed with SLE in accordance with the Order of the Ministry for Health of Ukraine No. 676 of October 12, 2006 "On the Approval of Protocols for the Provision of Medical Care in the Rheumatology Specialty". The written consents to participate in comprehensive examinations in accordance with the principles of Helsinki Human Rights Declaration, Council of Europe Convention on Human Rights and Biomedicine, as well as the relevant laws of Ukraine, were duly obtained.

Routine laboratory tests were performed for all patients with SLE. In addition, we searched for the presence of IgM and IgG antibodies to CMV and EBV in blood serum to diagnose viral infections 
(by means of enzyme-linked immunosorbent assay using Cobas e411 Immunochemical Electrochemiluminescent Analyzer, Roche Diagnostics, Switzerland). To confirm the presence of active viral infection, viruses were detected by polymerase chain reaction. We found active CMV infection in 28 patients with SLE (23.33\%). Active EBV infection was diagnosed in 21 patients with SLE (17.50\%). The combination of active CMV and EBV infection was found in 15 patients with SLE (12.5\%).

To achieve the purpose of the study, we identified three steps: the first step was to analyze complaints in patients with SLE with active CMV infection and determine their diagnostic value, the second - in the analysis of complaints in patients with SLE with active EBV infection and clarify their diagnostic values and the third - in the analysis of complaints in patients with SLE with a combination of active CMV and EBV infection and clarification of their diagnostic value.

The statistical analysis was performed by calculating the chances of determining the phase of CMV and EBV infection in patients with SLE on the basis of a separate manifestation - a marker that can be detected during the initial examination of the patient. The probability of active infection was determined using indicators of sensitivity, specificity, and accuracy. Sensitivity (true positive rate) reflects the proportion of positive results that correctly identify the sick subject as sick. Specificity (true negative rate) reflects the proportion of negative results that correctly identify the healthy subject as such, and accuracy reflects the proportion of correct diagnoses based on the information about a positive or negative result. We also determined odds ratio (an indicator that shows how much the absence or presence of a certain manifestation is associated with the presence or absence of a specific disease in the statistical group), the coefficient of association (a statistic that shows how close the stochastic relationship between qualitative manifestations, alternative random variables is) [1]. The data was processed on a personal computer in MS Excel and SPSS applications on the basis of contingency tables with the calculation of diagnostic value, as well as in Statistica 6.0 aplication using the methods of descriptive statistics The relationship between active infection and a particular complaint was considered to be confirmed when the absolute value of the association coefficient exceeded 0.5 (or 0.3 for the contingency coefficient).

\section{Research results.}

The results of the first step - the analysis of the complaints of patients with SLE and high levels of antibodies to CMV - are shown in Table. 1.

Table 1. The prevalence of complaints in the patients with SLE and active CMV

\begin{tabular}{|c|c|c|c|c|}
\hline \multirow[t]{2}{*}{ Complaints of patients with SLE } & \multicolumn{2}{|c|}{$\begin{array}{l}\text { Patients with SLE and active } \\
\text { CMV infection }\end{array}$} & \multicolumn{2}{|c|}{$\begin{array}{c}\text { Patients with SLE without active } \\
\text { CMV infection }\end{array}$} \\
\hline & $\mathrm{n}$ & $\%$ & $\mathrm{n}$ & $\%$ \\
\hline 1 & 2 & 3 & 4 & 5 \\
\hline Joint pain & 28 & 100.00 & 62 & 67.39 \\
\hline Muscle pain (myalgia) & 26 & 92.86 & 56 & 60.87 \\
\hline Morning stiffness & 7 & 25.00 & 36 & 39.13 \\
\hline New rashes & 20 & 71.43 & 62 & 67.39 \\
\hline Hair loss & 6 & 2143 & 33 & 35.87 \\
\hline Itchy skin & 6 & 21.43 & 12 & 13.04 \\
\hline Acrohypothermy & 20 & 71.43 & 41 & 44.57 \\
\hline Fever & 17 & 60.71 & 31 & 33.70 \\
\hline Edema & 4 & 14.29 & 8 & 8.70 \\
\hline Dyspnea & 8 & 28.57 & 33 & 35.87 \\
\hline Cough & 2 & 7.14 & 16 & 17.39 \\
\hline Arterial hypertension & 6 & 21.43 & 35 & 38.04 \\
\hline Palpitations & 7 & 25.00 & 18 & 19.57 \\
\hline Heart pain & 6 & 21.43 & 10 & 10.87 \\
\hline Feeling of skipping beats & 3 & 10.71 & 10 & 10.87 \\
\hline
\end{tabular}


Continuation of table 1 .

\begin{tabular}{|l|c|c|c|c|}
\hline \multicolumn{1}{|c|}{1} & 2 & 3 & 4 & 5 \\
\hline Nausea & 6 & 21.43 & 18 & 19.57 \\
\hline Bitter taste in the mouth & 10 & 35.71 & 28 & 30.43 \\
\hline Epigastric pain & 8 & 28.57 & 24 & 26.09 \\
\hline $\begin{array}{l}\text { Right upper quadrant } \\
\text { abdominal pain }\end{array}$ & 6 & 21.43 & 19 & 20.65 \\
\hline Appetite disorders & 14 & 50.00 & 32 & 34.78 \\
\hline Painful urination & 6 & 21.43 & 13 & 14.13 \\
\hline Dry eye & 16 & 57.14 & 34 & 36.96 \\
\hline Fingers numbness & 3 & 10.71 & 6 & 6.52 \\
\hline Headaches & 14 & 50.00 & 34 & 36.96 \\
\hline Sleep disorders & 6 & 21.43 & 9 & 9.78 \\
\hline Mood swings & 8 & 28.57 & 14 & 15.22 \\
\hline
\end{tabular}

Analyzing the complaints of patients with SLE and CMV infection, we found joint pain in all patients with SLE and active CMV infection (100.0\%) and in most patients with SLE without active CMV infection $(67.39 \%)$. The sensitivity of the complaint as a marker of active CMV infection reached $100.00 \%$, specificity $-31.11 \%$, accuracy $-47.46 \%$. We found statistically significant relationship between the presence of this marker and belonging to the group with active CMV infection (direct relationship, coefficient of contingency $=0.31$ ). Complaints of muscle pain (myalgia) were voiced by 26 patients with SLE and active CMV infection $(92,86 \%)$ and by 56 patients without active CMV infection (60.80\%). These complaints were 8.36 times more prevalent in patients with SLE and active CMV infection (sensitivity $-92.86 \%$, specificity $-39.13 \%$, accuracy $-51.67 \%$ ). We found a statistically significant relationship between this marker and belonging to the group with active CMV infection (direct relationship, coefficient of association $=0.79$ ). The complaints of morning stiffness were voiced by 7 patients with SLE and active CMV infection (25.00\%). The same complaints were voiced by 36 patients with SLE without active CMV infection (39.13\%). $71.43 \%$ of patients with SLE and active CMV infection and $67.39 \%$ of patients without active CMV infection complained of skin rashes. We received the complaints of hair loss only from 6 patients with SLE and active CMV infection (21.43\%) and from 33 patients with SLE without active CMV infection (35.87\%). 20 patients with SLE and active CMV infection (71,43\%) and 41 patients with SLE without active CMV infection (44,57\%) complained of acrohypothermy. These complaints were more prevalent in patients with SLE and active CMV infection than in patients with SLE without active CMV infection (sensitivity $-71.43 \%$, specificity $-55.43 \%$, accuracy $-59.17 \%$ ), we found a statistically significant relationship between this marker and belonging to the group with active CMV infection (direct relationship, coefficient of association $=0.51$ ). $21.43 \%$ of patients with SLE and active CMV infection and $13.04 \%$ of patients without active CMV infection complained of itchy skin. 17 SLE patients with active CMV infection (60.71\%) complained of recurrent fever. 31 patients (33.70\%) with SLE without active CMV infection had the same complaints. Complaints of fever were 3.04 times more prevalent in patients with SLE and active CMV infection. The sensitivity of this marker for the detection of acute CMV infection was $60.61 \%$, specificity $-66.30 \%$, accuracy $65.00 \%$. We found a statistically significant relationship between the marker and belonging to the group with active CMV infection (direct relationship, coefficient of association $=0.51$ ). The complaints of the edema of the lower extremities were voiced by 4 patients (14.29\%) with SLE and active CMV infection. These complaints were also voiced by 8 patients with SLE without active CMV infection $(8.70 \%)$. Complaints of dyspnea were voiced by $28.57 \%$ of patients with SLE and active CMV infection and $35.87 \%$ of patients with SLE without active CMV infection. Complaints of cough were voiced by $7.14 \%$ of patients with SLE and active CMV infection and by $17.39 \%$ of patients with SLE without acute CMV infection. The cardiovascular system complaints included arterial hypertension in 6 patients with SLE and active CMV infection (21.43\%). The same complaints were voiced by 35 patients with SLE without active CMV infection (38.04\%). Complaints of palpitations were voiced by 7 patients with SLE and active CMV infection (25.00\%) and by 18 SLE patients 
without active CMV infection (19.57\%). Heart pain was detected in 6 patients with SLE and active CMV infection (21.43\%). The same complaints were also voiced by 10 patients with SLE without active CMV infection (10.87\%). The feeling of skipping beats disturbed 3 patients with SLE with active CMV infection (10.71\%) and 10 patients without active CMV infection (10.87\%). On the part of the digestive system, 6 patients with SLE and active CMV infection (21.43\%) and 18 patients without active CMV infection (19.57\%) complained of nausea. The bitter taste in the mouth bothered 10 patients with SLE and active CMV infection (35.71\%) and 28 patients with SLE without active CMV infection (30.43\%). Complaints of epigastric pain were voiced by 8 patients with SLE and active CMV infection (28.57\%) and 24 patients with SLE without active CMV infection (26.09\%). Complaints of right upper quadrant abdominal pain were voiced by 6 patients with SLE and active CMV infection (21.43\%) and by 19 patients with SLE without active CMV infection (20.65\%). Appetite disorders bothered 50.00\% of patients with SLE and active CMV infection and $34.78 \%$ of patients with SLE without active CMV infection. Complaints of painful urination were voiced by 6 patients with SLE and active CMV infection (21.43\%) and by 13 patients with SLE without active CMV infection (14.13\%). 57.14\% of patients with SLE and acute CMV infection and $36.96 \%$ of patients with SLE without active CMV infection complained of having dry eyes. Complaints of fingers numbness were voiced by 3 patients with active CMV infection (10.71\%) and by 6 patients without active CMV infection (6.52\%). 14 patients with SLE and active CMV infection (50.00\%) and 34 patients without active CMV infection (36.96\%) complained of headaches. Sleep disorders bothered 6 SLE patients with active CMV infection (21.43\%) and 9 SLE patients without active CMV infection (9.78\%). Complaints of mood swings were voiced by $28.57 \%$ of SLE patients with active CMV infection and $9.78 \%$ of SLE patients without active CMV infection.

The results of our research to determine the diagnostic value of complaints in patients with SLE and active CMV infection are shown in Table 2.

Table 2. The diagnostic value of complaints in patients with SLE and active CMV infection

\begin{tabular}{|l|c|c|c|c|c|c|}
\hline $\begin{array}{l}\text { Complaints of } \\
\text { patients with SLE }\end{array}$ & Sensitivity & Specificity & Accuracy & $\begin{array}{c}\text { Odds } \\
\text { ratio }\end{array}$ & $\begin{array}{c}\text { Coefficient of } \\
\text { association }\end{array}$ & $\begin{array}{c}\text { Coefficient of } \\
\text { contingency }\end{array}$ \\
\hline Joint pain & 100,00 & 31,11 & - & 47,46 & 1 & 7 \\
\hline $\begin{array}{l}\text { Muscle pain } \\
\text { (myalgia) }\end{array}$ & 92,86 & 39,13 & 51,67 & 8,36 & 0,79 & - \\
\hline Morning stiffness & 26,92 & 60,87 & 53,39 & 0,57 & $-0,27$ & - \\
\hline New rashes & 71,43 & 32,61 & 41,67 & 1,21 & 0,09 & - \\
\hline Hair loss & 21,43 & 64,13 & 54,17 & 0,49 & $-0,34$ & - \\
\hline Itchy skin & 21,43 & 86,96 & 71,67 & 1,82 & 0,29 & - \\
\hline Acrohypothermy & 71,43 & 55,43 & 59,17 & 3,11 & 0,51 & - \\
\hline Fever & 60,71 & 66,30 & 65,00 & 3,04 & 0,51 & - \\
\hline Edema & 14,29 & 92,16 & 75,38 & 1,96 & 0,32 & - \\
\hline Dyspnea & 28,57 & 64,13 & 55,83 & 0,72 & $-0,17$ & - \\
\hline Cough & 7,14 & 82,61 & 65,00 & 0,37 & $-0,46$ & - \\
\hline Arterial hypertension & 21,43 & 61,96 & 52,50 & 0,44 & $-0,38$ & - \\
\hline Palpitations & 25,00 & 80,43 & 67,50 & 1,37 & 0,16 & - \\
\hline $\begin{array}{l}\text { Feeling of skipping } \\
\text { beats }\end{array}$ & 10,71 & 89,13 & 70,83 & 0,98 & $-0,01$ & - \\
\hline Heart pain & 21,43 & 89,13 & 73,33 & 2,24 & 0,38 & - \\
\hline Nausea & 21,43 & 80,43 & 66,67 & 1,21 & 0,06 & - \\
\hline $\begin{array}{l}\text { Bitter taste in the } \\
\text { mouth }\end{array}$ & 35,71 & 69,57 & 61,67 & 1,27 & 0,12 & - \\
\hline Epigastric pain & 28,57 & 73,91 & 63,33 & 1,13 & 0,06 & - \\
\hline $\begin{array}{l}\text { Right upper quadrant } \\
\text { abdominal pain }\end{array}$ & 21,43 & 79,35 & 65,83 & 1,05 & 0,02 & - \\
\hline
\end{tabular}


Continuation of table 2 .

\begin{tabular}{|l|c|c|c|c|c|c|}
\hline \multicolumn{1}{|c|}{1} & 2 & 3 & 4 & 5 & 6 & 7 \\
\hline Appetite disorders & 50,00 & 65,22 & 61,67 & 1,88 & 0,30 & - \\
\hline Painful urination & 21,43 & 85,87 & 70,83 & 1,66 & 0,25 & - \\
\hline Dry eye & 57,14 & 65,66 & 63,78 & 2,55 & 0,44 & - \\
\hline Fingers numbness & 10,71 & 93,48 & 74,17 & 1,72 & 0,26 & - \\
\hline Headaches & 50,00 & 63,04 & 60,00 & 1,71 & 0,43 & - \\
\hline Sleep disorders & 21,43 & 90,22 & 74,17 & 2,52 & 0,38 & - \\
\hline Mood swings & 28,57 & 84,78 & 71,67 & 2,23 & $-0,40$ & - \\
\hline
\end{tabular}

Thus, we found that joint pain, muscle pain, acrohypothermy and fever were manifestations of active CMV infection in patients with SLE.

The results of the second step - the analysis of the complaints of patients with SLE and active EBV - are shown in Table 3.

Table 3. The prevalence of complaints in patients with SLE with active EBV infection

\begin{tabular}{|c|c|c|c|c|}
\hline \multirow{2}{*}{$\begin{array}{l}\text { Complaints of patients } \\
\text { with SLE }\end{array}$} & \multicolumn{2}{|c|}{$\begin{array}{c}\text { Patients with SLE and active } \\
\text { EBV infection }\end{array}$} & \multicolumn{2}{|c|}{$\begin{array}{l}\text { Patients with SLE without active } \\
\text { EBV infection }\end{array}$} \\
\hline & $\mathrm{n}$ & $\%$ & $\mathrm{n}$ & $\%$ \\
\hline Joint pain & 17 & 80.95 & 73 & 73.74 \\
\hline Muscle pain (myalgia) & 21 & 100.00 & 61 & 61.62 \\
\hline Morning stiffness & 11 & 52.38 & 32 & 32.32 \\
\hline New rashes & 18 & 85.71 & 64 & 64.65 \\
\hline Hair loss & 11 & 52.38 & 28 & 28.28 \\
\hline Itchy skin & 8 & 38.10 & 53 & 53.54 \\
\hline Acrohypothermy & 6 & 28.57 & 12 & 12.12 \\
\hline Fever & 15 & 71.43 & 37 & 37.38 \\
\hline Edema & 3 & 14.29 & 9 & 9.09 \\
\hline Dyspnea & 11 & 52.38 & 30 & 30.30 \\
\hline Cough & 4 & 19.05 & 14 & 14.14 \\
\hline Arterial hypertension & 9 & 42.86 & 32 & 32.32 \\
\hline Palpitations & 7 & 33.33 & 18 & 18.18 \\
\hline Heart pain & 4 & 19.05 & 9 & 9.09 \\
\hline Feeling of skipping beats & 5 & 23.81 & 11 & 11.11 \\
\hline Nausea & 4 & 19.05 & 20 & 20.20 \\
\hline Bitter taste in the mouth & 9 & 42.86 & 29 & 29.29 \\
\hline Epigastric pain & 7 & 33.33 & 25 & 25.25 \\
\hline $\begin{array}{l}\text { Right upper quadrant } \\
\text { abdominal pain }\end{array}$ & 7 & 33.33 & 18 & 18.18 \\
\hline Appetite disorders & 12 & 57.14 & 34 & 34.34 \\
\hline Painful urination & 6 & 28.57 & 13 & 13.13 \\
\hline Dry eye & 13 & 61.60 & 37 & 37.37 \\
\hline Fingers numbness & 2 & 9.52 & 7 & 7.07 \\
\hline Headaches & 12 & 57.14 & 36 & 36.36 \\
\hline Sleep disorders & 9 & 42.86 & 6 & 6.06 \\
\hline Mood swings & 10 & 47.62 & 12 & 12.12 \\
\hline
\end{tabular}


Analyzing the complaints of patients with SLE infected with active EBV, we recorded joint pain in 17 patients with SLE and active EBV infection (80.95\%) and 73 patients with SLE without active EBV infection (73.74\%). Complaints of muscle pain were voiced by all patients with SLE and active EBV infection $(100.00 \%)$ and by 61 patients with SLE without active EBV infection (61.62\%). The sensitivity of these complaints as a marker to detect active EBV infection was $100.00 \%$, specificity $-38.38 \%$, accuracy $-49.17 \%$. We found a statistically significant relationship between the marker and belonging to the group with active EBV infection (direct relationship, coefficient of contingency $=0.31$ ). Complaints of morning stiffness were voiced by 11 patients with SLE and active EBV infection (52.38\%). The same complaints were voiced by 32 patients with SLE without active EBV infection (32.32\%). 85.71\% of patients with SLE and active EBV infection and $64.65 \%$ of patients with SLE without active EBV infection complained of skin rashes. These complaints were 3.28 times more prevalent in patients with SLE and active EBV infection than without it (sensitivity $85.71 \%$, specificity $-35.35 \%$, accuracy $-44.17 \%$ ). We found a statistically significant relationship between the complaints of skin rashes and belonging to the group with active EBV infection (direct relationship, coefficient of association $=0.53$ ). We found complaints of hair loss in 11 patients with SLE and active EBV infection (52.38\%) and 28 patients with SLE without acute EBV infection (28.28\%). Complaints of acrohypothermy were voiced by 8 patients with SLE and active EBV infection (38.10\%) and by 53 patients with SLE without active EBV infection (53.54\%). 15 patients with SLE and active EBV infection (71.43\%) complained of periodic fever. The same complaints were voiced by 37 patients with SLE without active EBV infection (37.38\%). Thus, complaints of fever were 4.19 times more prevalent in patients with SLE and active EBV infection. The sensitivity of this marker for the detection of acute EBV infection was $71.43 \%$, specificity $-62.63 \%$, accuracy $64.17 \%$. We found a statistically significant relationship between the marker and belonging to the group with active CMV infection (direct relationship, coefficient of association $=0.61$ ). Complaints of edema of the lower extremities were voiced by the 3 patients with SLE and active EBV infection (14.29\%). These complaints were also voiced by the 9 patients with SLE without active EBV infection (9.09\%). Complaints of dyspnea were voiced by $52.38 \%$ of patients with SLE and active EBV infection and $30.30 \%$ of patients with SLE without active EBV infection. Complaints of cough were voiced by $19.05 \%$ of patients with SLE and active EBV infection and by $14.14 \%$ of patients with SLE without acute EBV infection. Complaints of arterial hypertension were voiced by 9 patients with SLE and active EBV infection (42.86\%). The same complaints were voiced by 32 patients with SLE without active EBV infection (32.32\%). Complaints of palpitations were voiced by the 7 patients with SLE and active EBV infection (33.33\%) and by 18 patients with SLE without active EBV infection (18.18\%). The feeling of skipping beats disturbed $19.05 \%$ patients with SLE with active CMV infection and $9.09 \%$ patients without active CMV infection (10.87\%). Only 5 patients with SLE and active EBV infection (23.81\%) complained of heart pain. The same complaints were voiced by 11 patients with SLE without active EBV infection (11.11\%). On the part of the digestive system, 4 patients with SLE and active EBV infection (19.05\%) and 20 patients with SLE without active EBV infection (20.20\%) complained of nausea. Bitter taste in the mouth bothered 9 patients with SLE and active EBV infection (42.86\%) and 29 patients with SLE without active EBV infection (29.29\%). Complaints of epigastric pain were voiced by 7 patients with SLE and active EBV infection (33.33\%) and 25 patients with SLE without active EBV infection (25.25\%). Complaints of right upper quadrant abdominal pain were voiced by 7 patient with SLE and active EBV infection (33.33\%) and by 18 patients with SLE without active EBV infection (18.18\%). Appetite disorders were reported in 12 patients with SLE and active EBV infection (57.14\%). The same complaints were found in $34.34 \%$ of patients with SLE without active EBV infection. Complaints of painful urination were voiced by 6 patients with SLE and active EBV infection $(28.57 \%)$ and by 13 patients without active EBV infection (13.13\%). 61.60\% of patients with SLE and acute EBV infection and 37.37\% of patients with SLE without active EBV infection complained of having dry eyes. Complaints of fingers numbness were voiced by 2 patients with SLE and active EBV infection (9.52\%) and by 7 patients with SLE without active EBV infection (7.07\%). 12 patients with SLE and active EBV infection (9.52\%) and 36 patients with SLE without active EBV infection (36.36\%) complained of headaches. Sleep disorders bothered 9 patients with SLE and active EBV infection (42.86\%) and 6 patients with SLE without active EBV infection (6.06\%). Such complaints were more prevalent in patients with active EBV infection than without it (sensitivity $-43.86 \%$, specificity $-93.94 \%$, accuracy $-85.00 \%$ ). There was a statistically 
significant relationship between the complaints of sleep disorders and belonging to the group with active EBV infection (direct relationship, coefficient of association $=0.84$ ). Complaints of mood swings were voiced by $47.62 \%$ of patients with SLE and active EBV infection and by $12.12 \%$ of patients with SLE without active EBV infection. These complaints were more prevalent in patients with SLE and active EBV infection (sensitivity $-47.62 \%$, specificity $-87.88 \%$, accuracy $-80.83 \%$ ). We found a statistically significant relationship between the marker and belonging to the group with active EBV infection (direct relationship, coefficient of association $=0.74$ ).

The results of our research to determine the diagnostic value of complaints in patients with SLE and active EBV infection are shown in Table 4.

Table 4. The diagnostic value of complaints in patients with SLE and active EBV infection

\begin{tabular}{|l|c|c|c|c|c|c|}
\hline $\begin{array}{l}\text { Complaints of } \\
\text { patients with SLE }\end{array}$ & Sensitivity & Specificity & Accuracy & $\begin{array}{c}\text { Odds } \\
\text { ratio }\end{array}$ & $\begin{array}{c}\text { Coefficient of } \\
\text { association }\end{array}$ & $\begin{array}{c}\text { Coefficient of } \\
\text { contingency }\end{array}$ \\
\hline Joint pain & 80,95 & 26,26 & 35,83 & 1,51 & 0,20 & - \\
\hline $\begin{array}{l}\text { Muscle pain } \\
\text { (myalgia) }\end{array}$ & 100,00 & 38,38 & 49,17 & - & 1,00 & 0,31 \\
\hline Morning stiffness & 52,38 & 67,68 & 65,00 & 2,30 & 0,39 & - \\
\hline New rashes & 85,71 & 35,35 & 44,17 & 3,28 & 0,53 & - \\
\hline Hair loss & 52,38 & 71,71 & 68,33 & 2,79 & 0,47 & - \\
\hline Itchy skin & 38,10 & 46,46 & 45,00 & 0,53 & $-0,30$ & - \\
\hline Acrohypothermy & 28,57 & 87,88 & 77,50 & 2,90 & 0,49 & - \\
\hline Fever & 71,43 & 62,63 & 64,17 & 4,19 & 0,61 & - \\
\hline Edema & 14,29 & 90,91 & 77,50 & 1,67 & 0,25 & - \\
\hline Dyspnea & 52,38 & 69,70 & 66,67 & 2,53 & 0,43 & - \\
\hline Cough & 19,05 & 85,86 & 74,17 & 1,43 & 0,18 & - \\
\hline Arterial hypertension & 42,86 & 67,68 & 63,33 & 1,57 & 0,23 & - \\
\hline Palpitations & 33,33 & 81,82 & 73,33 & 2,25 & 0,38 & - \\
\hline $\begin{array}{l}\text { Feeling of skipping } \\
\text { beats }\end{array}$ & 19,05 & 90,91 & 78,33 & 2,35 & 0,40 & - \\
\hline Heart pain & 23,81 & 88,89 & 77,50 & 2,50 & 0,43 & - \\
\hline Nausea & 19,05 & 79,80 & 69,17 & 0,93 & $-0,04$ & - \\
\hline $\begin{array}{l}\text { Bitter taste in the } \\
\text { mouth }\end{array}$ & 42,86 & 70,71 & 65,83 & 1,81 & 0,29 & - \\
\hline Epigastric pain & 33,33 & 74,75 & 67,50 & 1,48 & 0,19 & - \\
\hline $\begin{array}{l}\text { Right upper quadrant } \\
\text { abdominal pain }\end{array}$ & 33,33 & 81,82 & 73,33 & 2,25 & 0,38 & - \\
\hline Appetite disorders & 57,14 & 65,66 & 64,17 & 2,55 & 0,44 & - \\
\hline Painful urination & 28,57 & 86,87 & 76,67 & 2,65 & 0,45 & - \\
\hline Dry eye & 61,90 & 63,64 & 63,33 & 2,84 & 0,48 & - \\
\hline Fingers numbness & 9,52 & 92,93 & 78,33 & 1,38 & 0,16 & - \\
\hline Headaches & 57,14 & 63,64 & 62,50 & 2,33 & 0,40 & - \\
\hline Sleep disorders & 42,86 & 93,94 & 85,00 & 11,63 & 0,84 & - \\
\hline Mood swings & 47,62 & 87,88 & 80,83 & 6,59 & 0,74 & - \\
\hline & & & & & & - \\
\hline
\end{tabular}

Thus, we found that among the complaints of patients with SLE, muscle pain, the appearance of new rashes, fever, sleep disturbances and mood swings are manifestations of active EBV infection.

The results of the analysis of the main complaints in patients with SLE with a combination of active CMV and EBV infection (third step) are presented in table. 5. 
Table 5. The prevalence of complaints in patients with SLE with a combination of active CMV and EBV infection

\begin{tabular}{|l|c|c|c|c|}
\hline \multirow{2}{*}{ Complaints of patients with SLE } & \multicolumn{2}{|c|}{$\begin{array}{c}\text { Patients with SLE and } \\
\text { combination of active CMV and } \\
\text { EBV infection }\end{array}$} & $\begin{array}{c}\text { Patients with SLE without } \\
\text { combination of active CMV } \\
\text { and EBV infection }\end{array}$ \\
\cline { 2 - 5 } & $\mathrm{n}$ & $\%$ & $\mathrm{n}$ & $\%$ \\
\hline Joint pain & 12 & 80.00 & 78 & 74.29 \\
\hline Muscle pain (myalgia) & 15 & 100.00 & 67 & 63.81 \\
\hline Morning stiffness & 5 & 33.33 & 38 & 36.19 \\
\hline New rashes & 9 & 60.00 & 73 & 69.52 \\
\hline Hair loss & 2 & 13.33 & 37 & 35.24 \\
\hline Itchy skin & 5 & 33.33 & 51 & 48.57 \\
\hline Acrohypothermy & 4 & 26.67 & 14 & 13.33 \\
\hline Fever & 10 & 66.67 & 42 & 40.00 \\
\hline Edema & 3 & 20.00 & 9 & 8.57 \\
\hline Dyspnea & 0 & 0.00 & 41 & 39.05 \\
\hline Cough & 1 & 6.67 & 17 & 16.19 \\
\hline Arterial hypertension & 8 & 53.33 & 33 & 31.43 \\
\hline Palpitations & 5 & 33.33 & 20 & 19.05 \\
\hline Heart pain & 3 & 20.00 & 10 & 9.52 \\
\hline Feeling of skipping beats & 4 & 26.67 & 12 & 11.43 \\
\hline Nausea & 5 & 33.33 & 19 & 18.10 \\
\hline Bitter taste in the mouth & 6 & 40.00 & 32 & 30.48 \\
\hline Epigastric pain & 3 & 20.00 & 12 & 11.43 \\
\hline Right upper quadrant abdominal pain & 5 & 33.33 & 20 & 19.05 \\
\hline Appetite disorders & 9 & 60.00 & 37 & 35.24 \\
\hline Painful urination & 4 & 26.67 & 15 & 14.29 \\
\hline Dry eye & 10 & 66.67 & 41 & 39.05 \\
\hline Fingers numbness & 2 & 13.33 & 7 & 6.67 \\
\hline Headaches & 9 & 60.00 & 39 & 37.14 \\
\hline Sleep disorders & 11 & 73.33 & 4 & 3.81 \\
\hline Mood swings & 9 & 60.00 & 13 & 12.38 \\
\hline & & & & \\
\hline
\end{tabular}

Analyzing the complaints in patients with SLE with a combination of active CMV and EBV infection, we recorded joint pain in 12 patients with SLE (80.00\%). The same complaints were found in 78 patients with SLE without a combination of active CMV and EBV infections (74.29\%). Myalgias were detected in all patients with SLE with a combination of active CMV and EBV infections (100.00\%) and in 67 patients without a combination of active CMV and EBV infection (63.81\%). Complaints of morning stiffness $(33.33 \%)$ were recorded in 5 patients with SLE with a combination of active CMV and EBV infection. The same complaints were found in 38 patients with SLE without a combination of active CMV and EBV infections (36.19\%). 60.00\% of patients with SLE with a combination of active CMV and EBV infection and $69.52 \%$ of patients without a combination of active CMV and EBV infection complained of skin rashes. We found complaints of hair loss in only 2 patients with SLE with active CMV and EBV infection (13.33\%) and in 37 patients with SLE without active CMV and EBV infection (35.24\%). Complaints of acrohypothermy were expressed by 5 patients with SLE with active CMV and EBV infection (33.33\%) and 51 patients with SLE without active CMV and EBV infection (48.57\%). We recorded complaints of itchy skin in only 4 patients with SLE with active CMV and EBV infection (26.67\%) and in 14 patients with SLE without 
active CMV and EBV infection (13.33\%). Among the patients we examined, 10 patients with SLE with active CMV and EBV infection (66.67\%) complained of periodic fever. In the group of patients with SLE without active CMV and EBV infection, the same complaints were expressed by 42 patients (40.00\%). Complaints of fever 3.00 times more common in patients with SLE with active CMV and EBV infection. The sensitivity of the marker for the detection of active CMV and EBV infection is $66.67 \%$, specificity $-60.00 \%$, accuracy $-60.83 \%$. A statistically significant association (direct relationship, coefficient of association $=0.50$ ) was established between the marker and belonging to the group with active CMV and EBV infection. Complaints of edema of the lower extremities (20.00\%) were found in 3 patients with SLE with active CMV and EBV infection. These complaints were recorded in 9 patients with SLE without active CMV and EBV infection (8.57\%). Complaints of shortness of breath were recorded only in patients with SLE with active CMV and EBV infection (39.05\%). In 6.67\% of patients with SLE with active CMV and EBV infection and in $16.19 \%$ of patients with SLE without active CMV and EBV infection, complaints of cough were recorded. Among the complaints from the cardiovascular system in 8 patients with SLE with active CMV and EBV infection revealed an increase in blood pressure (53.33\%). The same complaints were expressed by 33 patients with SLE without active CMV and EBV infection (31.43\%). Among patients with SLE, complaints of palpitations were recorded in 5 patients with SLE with active CMV and EBV infection (33.33\%) and in 20 patients without active CMV and EBV infection (19.05\%). Pain in the heart was detected in 4 patients with SLE with active CMV and EBV infection (26.67\%). The same complaints were expressed by 12 patients with SLE without active CMV and EBV infection (11.43\%). On the part of the digestive system, 5 patients with SLE with active CMV and EBV infection (33.33\%) and 19 patients without active CMV and EBV infection (18.10\%) complained of nausea. The feeling of bitterness in the oral cavity bothered 6 patients with SLE with active CMV and EBV infections (40.00\%) and 32 patients with SLE without active CMV and EBV infections (30.48\%). Complaints of epigastric pain were expressed by 3 patients with SLE with active CMV and EBV infections (20.00\%) and 12 patients with SLE without active CMV and EBV infections (11.43\%). Complaints of pain in the right hypochondrium were recorded in 5 patients with SLE with active CMV and EBV infection (33.33\%) and in 20 patients with SLE without active CMV and EBV infections (19.05\%). Appetite disorders were recorded in 9 patients with SLE with active CMV and EBV infection (60.00\%). The same complaints were found in 37 patients with SLE without active CMV and EBV infection (35.24\%). Complaints of discomfort during urination were recorded in 4 patients with SLE with active CMV and EBV infection (26.67\%) and in 15 patients without active CMV and EBV infection (14.29\%). 66.67\% of patients with SLE with active CMV and EBV infection and 39.05\% of patients with SLE without active CMV and EBV infection complained of dry eyes. The sensitivity of the complaint for the detection of active CMV and EBV infection is $66.67 \%$, specificity - $60.95 \%$, accuracy $-61.67 \%$. There was a statistically significant association (direct relationship, coefficient of association $=0.51$ ) between the marker and belonging to the group with active CMV and EBV infection. Among patients with SLE, complaints of finger numbness were recorded in 2 patients with active CMV and EBV infection (13.33\%) and in 7 patients without active CMV and EBV infection (6.67\%). Nine patients with SLE with active CMV and EBV infection (60.00\%) and 39 patients without active CMV and EBV infection (37.14\%) complained of headache. Sleep disorders disturbed 11 patients with SLE with active CMV and EBV infection (73.33\%) and 4 patients with SLE without active CMV and EBV infection (3.81\%). Such a complaint is more often recorded in patients with active CMV and EBV infection than without it (sensitivity - 73.33\%, specificity - 96.19\%, accuracy 93.33\%). The presence of complaints of sleep disturbances is related to belonging to the group with active CMV and EBV infection (direct connection, association coefficient 0.97). Complaints of mood swings were found in $60.00 \%$ of patients with SLE with active CMV and EBV infection and in $12.38 \%$ of patients with SLE without active CMV and EBV infection. These complaints are more common in patients with SLE with active CMV and EBV infection (sensitivity - 60.00\%, specificity $87.62 \%$, accuracy $-84.17 \%$ ). We found a significant association between the marker and belonging to the group with active CMV and EBV infection (direct relationship, coefficient of association $=0.83$ ). The results of our study to study the diagnostic value of complaints in patients with SLE with active EBV infection are presented in table 6. 
Table 6. The diagnostic value of complaints in patients with SLE with a combination of active CMV and EBV infection

\begin{tabular}{|l|c|c|c|c|c|c|}
\hline $\begin{array}{l}\text { Complaints of } \\
\text { patients with SLE }\end{array}$ & Sensitivity & Specificity & Accuracy & $\begin{array}{c}\text { Odds } \\
\text { ratio }\end{array}$ & $\begin{array}{c}\text { Coefficient of } \\
\text { association }\end{array}$ & $\begin{array}{c}\text { Coefficient of } \\
\text { contingency }\end{array}$ \\
\hline Joint pain & 80,00 & 25,71 & 32,50 & 1,38 & 0,16 & - \\
\hline $\begin{array}{l}\text { Muscle pain } \\
\text { (myalgia) }\end{array}$ & 100,00 & 36,19 & 44,17 & - & 1 & 0,26 \\
\hline Morning stiffness & 33,33 & 63,81 & 60,00 & 0,88 & $-0,06$ & - \\
\hline New rashes & 60,00 & 30,48 & 34,17 & 0,66 & $-0,21$ & - \\
\hline Hair loss & 13,33 & 64,76 & 58,33 & 0,28 & $-0,56$ & - \\
\hline Itchy skin & 33,33 & 51,43 & 49,17 & 0,53 & $-0,31$ & - \\
\hline Acrohypothermy & 26,67 & 86,67 & 79,17 & 2,36 & 0,41 & - \\
\hline Fever & 66,67 & 60,00 & 60,83 & 3,00 & 0,50 & - \\
\hline Edema & 20,00 & 91,43 & 82,50 & 2,67 & 0,45 & - \\
\hline Dyspnea & 0,00 & 60,95 & 53,33 & 0,00 & $-1,00$ & $-0,27$ \\
\hline Cough & 6,67 & 83,81 & 74,17 & 0,37 & $-0,46$ & - \\
\hline Arterial hypertension & 53,33 & 68,57 & 66,67 & 2,49 & 0,43 & - \\
\hline Palpitations & 33,33 & 80,95 & 75,00 & 2,13 & 0,36 & - \\
\hline $\begin{array}{l}\text { Feeling of skipping } \\
\text { beats }\end{array}$ & 20,00 & 90,48 & 81,67 & 2,38 & 0,41 & - \\
\hline Heart pain & 26,67 & 88,57 & 80,83 & 2,82 & 0,48 & - \\
\hline Nausea & 33,33 & 81,90 & 75,83 & 2,26 & 0,39 & - \\
\hline $\begin{array}{l}\text { Bitter taste in the } \\
\text { mouth }\end{array}$ & 40,00 & 69,52 & 65,83 & 1,52 & 0,21 & - \\
\hline Epigastric pain & 20,00 & 88,57 & 80,00 & 1,94 & 0,32 & - \\
\hline $\begin{array}{l}\text { Right upper quadrant } \\
\text { abdominal pain }\end{array}$ & 33,33 & 80,95 & 75,00 & 2,13 & 0,36 & - \\
\hline Appetite disorders & 60,00 & 64,76 & 64,17 & 2,76 & 0,47 & - \\
\hline Painful urination & 26,67 & 85,71 & 78,33 & 2,18 & 0,37 & - \\
\hline Dry eye & 66,67 & 60,95 & 61,67 & 3,12 & 0,51 & - \\
\hline Fingers numbness & 13,33 & 93,33 & 83,33 & 2,15 & 0,37 & - \\
\hline Headaches & 60,00 & 62,86 & 62,50 & 2,54 & 0,43 & - \\
\hline Sleep disorders & 73,33 & 96,19 & 93,33 & 69,44 & 0,97 & - \\
\hline Mood swings & 60,00 & 87,62 & 84,17 & 10,62 & 0,83 & - \\
\hline & & & & & & - \\
\hline
\end{tabular}

Thus, we found that among the complaints of patients with SLE fever, dry eyes, sleep disturbances and mood swings are a manifestation of a combination of active CMV and EBV infection.

Conclusions. About the presence of active cytomegalovirus infection in patients with systemic lupus erythematosus among the main complaints is significantly more often evidenced by the presence of myalgias (coefficient of association 0.79), or fever (0.51), or acrohypothermy (coefficient of association 0.51), or arthralgia (coefficient of contingency 0.31). About the presence of active Epstein - Barr viral infection in patients with systemic lupus erythematosus among the main complaints significantly more often indicates the presence of sleep disorders (coefficient of association 0.84 ), or mood swings (0.74), or fever (coefficient of association 0.61), or the appearance of new rashes (0.53), or myalgias (coefficient of contingency 0.31), About the presence of a combination of active cytomegalovirus and virus Epstein- Barr infection in patients with systemic lupus erythematosus among the main complaints significantly more often indicates complaints of sleep disturbances 
(coefficient of association 0.97), or mood swings (0.83), or a feeling of dryness in the eyes (0.51), or fever (0.50), which can be used in the diagnostic algorithm.

The established patterns of complaints in patients with systemic lupus erythematosus can reasonably be suspected the presence of active CMV and Epstein - Barr viral infection, the final verification of which requires the use of direct serological tests.

\section{REFERENCES}

1. Longnecker RM (2013), 'Epstein-Barr virus,' Fields Virology, 5th edn. Wolters Kluwer/Lippincott Williams \& Wilkins, Philadelphia, PA, 2013; 1898-959.

2. Draborg AH, Duus K, Houen G. (2012) 'Epstein-Barr virus and systemic lupus erythematosus,' Clin Dev Immunol; 2012:370516.

3. Mohamed AE, Hasen AM, Mohammed GF, Elmaraghy NN. (2015) Real-Time PCR of cytomegalovirus and Epstein-Barr virus in adult Egyptian patients with systemic lupus erythematosus. Int J Rheumc Dis. 18(4):452-458. 